\title{
Risk factors and their impact on carotid intima-media thickness in young and middle-aged ischemic stroke patients and controls: The Norwegian Stroke in the Young Study
}

Annette Fromm ${ }^{1,2^{*}}$, Øystein Ariansen Haaland ${ }^{3}$, Halvor Naess ${ }^{1,2,4}$, Lars Thomassen ${ }^{1,2}$ and Ulrike Waje-Andreassen ${ }^{1}$

\begin{abstract}
Background: Vascular morbidity and mortality due to cardiovascular disease (CVD) are high after ischemic stroke at a young age. Data on carotid intima-media thickness (CIMT) as marker of atherosclerosis are scarce for young stroke populations. In this prospective case-control study, we examined CIMT, the burden of vascular risk factors (RF) and their associations among young and middle-aged ischemic stroke patients and controls. We aimed to detect clinical and sub-clinical arterial disease.
\end{abstract}

Methods: This study was conducted in 150 patients aged 15-60 years and 84 controls free of CVD. We related RF to ultrasonographic B-mode CIMT-measurements obtained from 12 standardized multiangle measurements in the common carotid artery (CCA), carotid bifurcation (BIF) and internal carotid artery (ICA).

Results: RF burden was higher among patients than among controls $(p<0.001)$. In multivariate analyses of all 234 participants, increased CIMT was associated with age in each carotid segment. Incident stroke was associated with increased ICA-IMT. ICA-IMT increase was associated with a family history of CVD among patients aged 15-44 years, and with RF at mid-age. The overall CIMT difference between patients and controls was 12\% for CCA, 17\% for BIF and 29\% for ICA. Further, increased CCA-IMT was associated with male sex and hypertension. Increased BIF-IMT was associated with dyslipidemia, coronary heart disease and smoking. Increased ICA-IMT was associated with dyslipidemia and stroke.

Conclusions: Ischemic stroke is associated with increased ICA-IMT, related to a family history of CVD among patients aged $<45$ years, and to increasing RF burden with increasing age. Preventive strategies and aggressive RF treatment are indicated to avoid future cardiovascular events.

Trial registration: NOR-SYS is registered in ClinicalTrials.gov (NCT01597453).

Keywords: Young stroke, Ischemic stroke, Risk factors, Carotid intima-media thickness, Atherosclerosis, Ultrasound

\section{Background}

High rates of recurrent stroke, vascular morbidity and mortality due to cardiovascular disease (CVD) [1-3] clarify the need to detect and treat vascular risk factors and incipient atherosclerosis at early stages. Carotid intima-media thickness (cIMT) is a surrogate marker of atherosclerosis $[4,5]$,

\footnotetext{
* Correspondence: annette.fromm@helse-bergen.no

${ }^{1}$ Centre for Neurovascular Diseases, Department of Neurology, Haukeland University Hospital, Bergen, Norway

${ }^{2}$ Department of Clinical Medicine, University of Bergen, Bergen, Norway

Full list of author information is available at the end of the article
}

and ultrasound screening a valuable tool for cardiovascular risk prediction [6,7]. Nevertheless, cIMT data obtained from young stroke populations are scarce. We aimed to assess the prevalence of clinical and subclinical carotid artery atherosclerosis and the impact of vascular risk factors (RF) among young ischemic stroke patients compared to CVDfree controls in a case-control study.

\section{Methods}

The Norwegian Stroke in the Young Study (NOR-SYS) is a prospective three-generation study with longitudinal 
follow-up design. NOR-SYS combines medical history and RF ascertainment by standardized questionnaires with clinical, laboratory, neuroradiological, cardiological and complex ultrasonographic data [8]. This analysis contains data from 150 patients and 84 controls included in NOR-SYS between September 2010 and June 2012.

\section{Approvals, registrations and consents}

NOR-SYS is conducted according to the Declaration of Helsinki, approved by the Regional Committee for Medical and Health Research Ethics, Western-Norway (2010/74), and registered in ClinicalTrials.gov (NCT01597453). Written informed consent was obtained from all participants or their legal representatives.

\section{Subject selection}

Patients aged 15-60 years with documented acute ischemic stroke and residency in Hordaland county, Norway, were included. Two patients refused study participation. Seven patients were excluded; three due to incomplete neurosonographic data set, and four non-Caucasian patients. Patients' partners served as controls due to their function as reference persons for joint offspring in future analyses. Of 123 available partners, 63 (70.8\%) females and 21 (61.8\%) males participated. Seven controls with prior cardiovascular events were excluded from statistical analysis.

\section{Risk factors}

Medical history of prior stroke, coronary heart disease (CHD: myocardial infarction, angina pectoris) and peripheral artery disease (PAD) was defined if diagnosed before admission or revealed during hospitalization for the qualifying stroke. Family history of CVD (stroke, CHD and/or PAD) was considered positive if reported for parents and/or siblings. Hypertension and diabetes mellitus were defined by diagnosis and/or treatment before

Table 1 Patient and control characteristics

\begin{tabular}{|c|c|c|c|c|c|c|c|c|}
\hline & & All & $15-44 y$ & $45-60 y$ & Females & Males & Age (p) & $\operatorname{Sex}(p)$ \\
\hline Patients & $\mathbf{N}$ & $150(100)^{*}$ & $45(30)^{*}$ & $105(70)^{*}$ & $49(32.7)^{*}$ & $101(67.3)^{*}$ & & \\
\hline Age (mean) & 150 & 48.5 & 35.8 & 54.0 & 46.3 & 49.6 & $<0.001$ & 0.075 \\
\hline Prior stroke & 150 & $13(8.7)$ & $1(2.2)$ & 12(11.4) & $6(12.2)$ & $7(6.9)$ & 0.017 & 0.325 \\
\hline $\mathrm{CHD}$ & 150 & $15(10.0)$ & $1(2.2)$ & 14(13.3) & $4(8.2)$ & $11(10.9)$ & 0.006 & 0.589 \\
\hline PAD & 150 & $8(5.3)$ & $1(2.2)$ & $7(6.7)$ & $2(4.1)$ & $6(5.9)$ & 0.181 & 0.617 \\
\hline Family CVD & 150 & 78(52.0) & $9(20.0)$ & $69(65.7)$ & $29(59.2)$ & $49(48.5)$ & $<0.001$ & 0.222 \\
\hline Diabetes & 150 & $16(10.7)$ & $2(4.4)$ & 14(13.3) & $7(14.3)$ & $9(8.9)$ & 0.053 & 0.357 \\
\hline Hypertension & 150 & $101(67.3)$ & 23(51.1) & 78(74.3) & $30(61.2)$ & $71(70.3)$ & 0.009 & 0.282 \\
\hline Dyslipidemia & 150 & $114(76.0)$ & $27(60.0)$ & 87(82.9) & $36(73.5)$ & $78(77.2)$ & 0.007 & 0.623 \\
\hline Smoking & 150 & 104(69.3) & 23(51.1) & $81(77.1)$ & $28(57.1)$ & $76(75.2)$ & 0.003 & 0.033 \\
\hline $\mathrm{BMI}>25$ & 144 & $99(68.8)$ & 28(62.2) & $71(67.6)$ & $30(61.2)$ & $69(68.3)$ & 0.941 & 0.542 \\
\hline Alcohol & 141 & & & & & & & \\
\hline None & & $9(6.4)$ & $5(11.1)$ & $4(3.8)$ & $4(8.2)$ & $5(5.0)$ & 0.173 & 0.476 \\
\hline Low & & 119(84.4) & $37(82.2)$ & $82(78.1)$ & $41(83.7)$ & $78(77.2)$ & 0.947 & 0.252 \\
\hline High & & $13(9.2)$ & $2(4.4)$ & $11(10.5)$ & $1(2.0)$ & $12(11.9)$ & 0.137 & 0.011 \\
\hline Controls & $\mathbf{N}$ & $84(100)^{*}$ & $21(25)^{*}$ & $63(75)^{*}$ & $63(75)^{*}$ & $21(25)^{*}$ & & \\
\hline Age (mean) & 84 & 49.3 & 36.6 & 53.5 & 48.8 & 50.6 & $<0.001$ & 0.453 \\
\hline Family CVD & 84 & 49(58.3) & $9(42.9)$ & $40(63.5)$ & $35(55.6)$ & $14(66.7)$ & 0.112 & 0.372 \\
\hline Diabetes & 84 & $9(10.7)$ & $1(4.8)$ & $8(12.7)$ & $5(7.9)$ & $4(19.0)$ & 0.218 & 0.249 \\
\hline Hypertension & 84 & 16(19.0) & $3(14.3)$ & 13(20.6) & $7(11.1)$ & $9(42.9)$ & 0.502 & 0.012 \\
\hline Dyslipidemia & 84 & $12(14.3)$ & $1(4.8)$ & $11(17.5)$ & $8(12.7)$ & $4(19.0)$ & 0.066 & 0.52 \\
\hline Smoking & 84 & $57(67.9)$ & 12(57.1) & $45(71.4)$ & $40(63.5)$ & $17(81.0)$ & 0.26 & 0.11 \\
\hline $\mathrm{BMI}>25$ & 80 & $45(56.3)$ & $11(52.4)$ & $34(54.0)$ & $31(49.2)$ & $14(66.7)$ & 0.872 & 0.147 \\
\hline Alcohol & 81 & & & & & & & \\
\hline None & & $4(4.9)$ & $0(0.0)$ & $4(6.3)$ & $3(4.8)$ & $1(4.8)$ & 0.045 & 0.989 \\
\hline Low & & 74(91.4) & 20(95.2) & $54(85.7)$ & $56(88.9)$ & $18(85.7)$ & 0.399 & 0.817 \\
\hline High & & $3(3.7)$ & $1(4.8)$ & $2(3.2)$ & $2(3.2)$ & $1(4.8)$ & 0.79 & 0.757 \\
\hline
\end{tabular}


hospital admission, or when revealed and treated during hospitalization for the qualifying stroke (blood pressure >140/90 mmHg; HbA1c >6.4\%). Dyslipidemia was defined as prior statin use, or when revealed during hospitalization (total cholesterol $>5.0 \mathrm{mmol} / \mathrm{L}$ and/ or low-density lipoprotein (LDL) $>3.0 \mathrm{mmol} / \mathrm{L}$ and/or high-density lipoprotein (HDL) $<1,0 \mathrm{mmol} / \mathrm{L}$ and/or triglycerides $>2.5 \mathrm{mmol} / \mathrm{L}$ ). Smoking was categorized as never-smoking or previous/current smoking. Alcohol consumption was categorized as never used/low (0-12 units/week) or high (>12 units/week). Bodymass index (BMI) was dichotomized as normal or $>25$. $\mathrm{RF}$ burden was defined as the number of RFs present $(0-10)$.

\section{Neurosonology and Duplex/Doppler ultrasound examinations}

Extracranial high-resolution sonography of the carotid arteries was performed with Philips iU22 and 9-3 MHz linear array transducer. Two patients were examined at the intensive care unit with a portable Phillips CX50 ultrasound system and $12-3 \mathrm{MHz}$ linear array transducer (both systems Philips Medical Systems, Bothell, WA, USA). Patients and controls were examined by two sonographers (AF, UWA), which both are trained and certified for the NOR-SYS duplex sonography research protocol in collaboration with the Vascular Imaging Centre, University Medical Centre, Utrecht, The Netherlands.

\section{Data reliability tests}

Reproducibility testing of cIMT measurements within (intra-observer) and between (inter-observer) sonographers of the research group, and between ultrasound equipment (inter-equipment) was performed applying both ultrasound systems. The intra-observer correlation of sonographers was 0.78-0.98 (mean absolute cIMT difference $0.02-0.08 \mathrm{~mm}$ ). The inter-observer correlation of sonographers was 0.83-0.93 (mean absolute cIMT difference $0.04-0.11 \mathrm{~mm}$ ). The inter-equipment correlation for iU22/CX50 was 0.94 (mean absolute cIMT difference $0.04 \mathrm{~mm}$ ). These results correlate with previously published studies [9-12].

\section{cIMT-measurements}

The methods of the cIMT measurements were previously described [8]. In total 12 far-wall cIMT measurements in the common carotid artery (CCA), the carotid bifurcation (BIF) and the internal carotid artery (ICA) were performed in each participant in the end-diastolic phase of the cardiac cycle, and mean cIMT values were acquired using Philips QLAB $^{\circ}$ (Philips Medical Systems, Bothell, WA, USA). In case of intra-segmental irregularities or plaques, maximum IMT or plaque thickness were measured additionally. Maximum segmental IMT values were used in statistical analysis. IMT values were defined as normal when $<0.8 \mathrm{~mm}$, as suspect for arterial disease when 0.8-0.99 $\mathrm{mm}[13,14]$, and as pathological when $\geq 1.0 \mathrm{~mm}[15,16]$. Plaques were defined as focal IMT measurements $>1.5 \mathrm{~mm}$ [17].

\section{Statistical analyses}

To allow for comparison to other studies [18-20], and in order to assess the influence of age and sex on IMT, our study population was grouped according to age (younger, 15-44 years; middle-aged, 45-60 years) and sex. Statistical analysis was performed using $\mathrm{R}$ version 3.0.0, and data

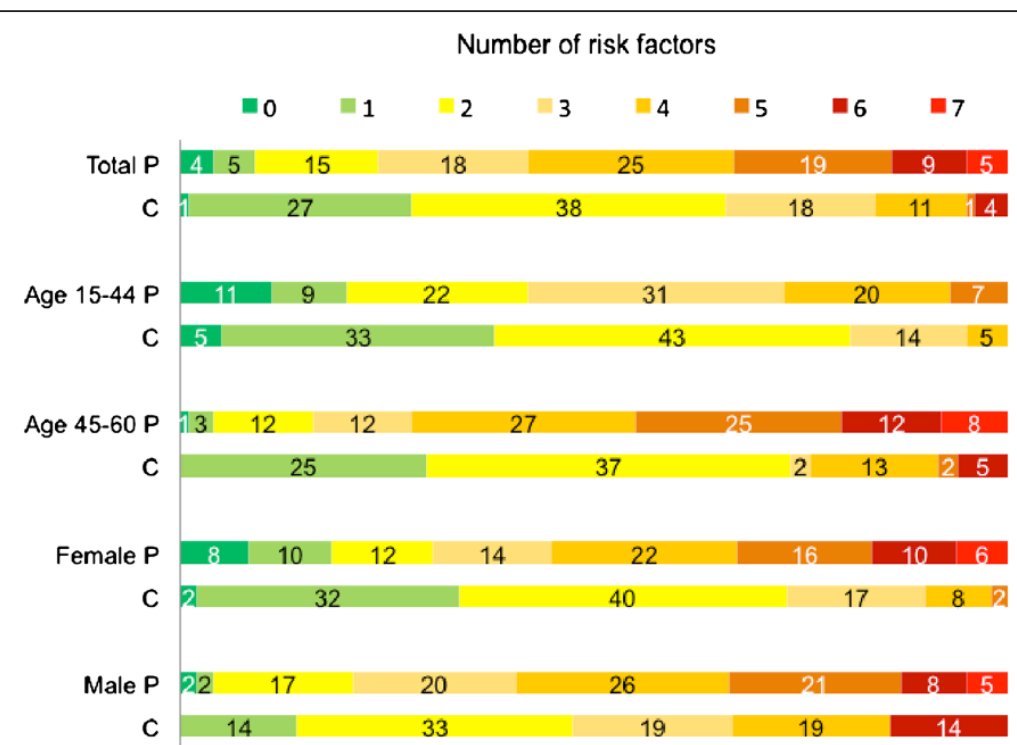

Figure 1 Risk factor burden. Data referred in percent. $\mathrm{P}=$ patients; $\mathrm{C}=$ controls. 
Table 2 Relative change in IMT between patients and controls and mean IMT values

\begin{tabular}{|c|c|c|c|c|c|c|c|c|}
\hline & NA & Total & $15-44$ y & $45-60 y$ & Females & Males & Age (p) & Sex $(p)$ \\
\hline \multicolumn{9}{|l|}{$\overline{C C A}$} \\
\hline Relative change & & $12(4-22)$ & $3(-9-15)$ & $19(8-30)$ & $4(-6-15)$ & $6(-9-23)$ & & \\
\hline Mean IMT patients & 1 & 0.85 & 0.63 & 0.94 & 0.75 & 0.89 & $<0.001$ & 0.003 \\
\hline Mean IMT controls & 0 & 0.73 & 0.61 & 0.77 & 0.7 & 0.82 & $<0.001$ & 0.008 \\
\hline \multicolumn{9}{|l|}{ BIF } \\
\hline Relative change & & $17(2-34)$ & $11(-9-36)$ & $23(7-43)$ & $9(-9-31)$ & $8(-16-38)$ & & \\
\hline Mean IMT patients & 11 & 1.34 & 0.84 & 1.54 & 1.23 & 1.39 & $<0.001$ & 0.079 \\
\hline Mean IMT controls & 2 & 1.12 & 0.7 & 1.26 & 1.04 & 1.34 & $<0.001$ & 0.067 \\
\hline \multicolumn{9}{|l|}{$I C A$} \\
\hline Relative change & & $29(12-49)$ & $20(-2-46)$ & $35(15-58)$ & $28(7-53)$ & $1(-23-31)$ & & \\
\hline Mean IMT patients & 30 & 0.97 & 0.63 & 1.1 & 0.9 & 1.0 & $<0.001$ & 0.312 \\
\hline Mean IMT controls & 14 & 0.73 & 0.47 & 0.83 & 0.64 & 1.06 & $<0.001$ & 0.021 \\
\hline
\end{tabular}

Data sorted by carotid segment, age group, and sex. Relative change presented in \% (CI); IMT presented in mm. CCA = Common carotid artery; BIF = Carotid bifurcation; ICA = Internal carotid artery; NA = Not available.

were formatted in STATA version 12.1. A t-test was applied when testing for differences between groups. The unadjusted analysis was conducted applying a univariate linear regression. Because each individual had two measurements per segment (right/left), a random intercept approach was used, utilizing the R-function $\operatorname{lmer}()$ from the lme4 package. Dependent variables (cIMT) were skewed towards low values, and a base $10 \log$ transform was applied to meet the assumptions of a linear regression. Hence, the relative change (RC) in cIMT per unit change in the independent variables (typically 0 or 1 ) could be obtained. Adjusted analyses were carried out accordingly, and multivariate logistic regression was applied. Simulations were used to determine the power to detect differences between controls and patients for $\mathrm{RC}$ ranging from
1.00 to 1.50 across each carotid segment. Fisher's exact test (based on simulations when appropriate) was applied when comparing tables or rows within tables.

\section{Results}

Population demographics are given in Table 1. Of patients, $30.0 \%$ were aged $15-44$ at study inclusion, and $32.7 \%$ were female. Of 84 controls, $25.0 \%$ were aged $15-44$ at study inclusion, and $75.0 \%$ were female.

\section{Risk factors}

Patients had a higher RF burden than controls in analysis of the entire study population $(\mathrm{p}<0.001)$ and in subgroup analyses (age 15-44: $\mathrm{p}=0.027$; age 45-60: $\mathrm{p}<0.001$; females: $\mathrm{p}<0.001$; males: $\mathrm{p}=0.021$ ), visualized in Figure 1 .

Table 3 Statistical significance for IMT increase in patients compared to controls

\begin{tabular}{|c|c|c|c|c|c|}
\hline & Total & $15-44 y$ & $45-60 y$ & Females & Males \\
\hline \multicolumn{6}{|l|}{$\overline{C C A}$} \\
\hline Relative change (unadjusted) & 0.005 & 0.669 & $<0.001$ & 0.404 & 0.465 \\
\hline Mean IMT (t-test) & $<0.001$ & 0.501 & $<0.001$ & 0.151 & 0.161 \\
\hline IMT distribution (Fisher's exact test) & 0.018 & 0.383 & 0.003 & 0.418 & 0.906 \\
\hline \multicolumn{6}{|l|}{$B I F$} \\
\hline Relative change (unadjusted) & 0.024 & 0.299 & 0.005 & 0.344 & 0.544 \\
\hline Mean IMT (t-test) & 0.006 & 0.030 & 0.005 & 0.108 & 0.760 \\
\hline IMT distribution (Fisher's exact test) & 0.111 & 0.447 & 0.010 & 0.202 & 0.027 \\
\hline \multicolumn{6}{|l|}{$I C A$} \\
\hline Relative change (unadjusted) & $<0.001$ & 0.079 & $<0.001$ & 0.008 & 0.947 \\
\hline Mean IMT (t-test) & $<0.001$ & 0.003 & 0.001 & 0.004 & 0.741 \\
\hline IMT distribution (Fisher's exact test) & $<0.001$ & 0.005 & $<0.001$ & 0.003 & 0.155 \\
\hline
\end{tabular}

Data presented as p-values, sorted by carotid segment, age group, and sex. Statistical significance presented in boldface. CCA = Common carotid artery; BIF = Carotid bifurcation; ICA = Internal carotid artery. Boldface represents statistical significant differences between patients and controls, mainly within the total population and among middle-aged participants, and as well among the young population and females in the ICA segment. 


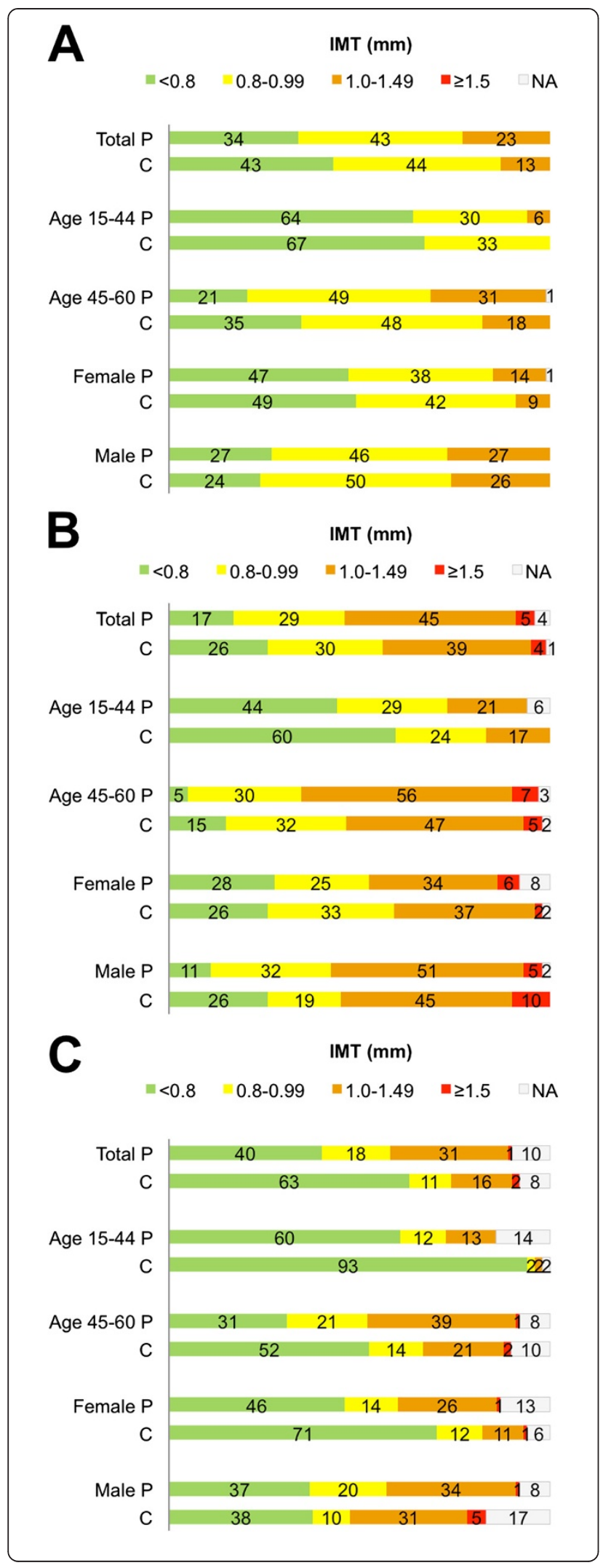

Figure 2 Segmental cIMT distribution in common carotid artery, carotid bifurcation and Internal carotid artery. Data referred in percent. $\mathbf{A}=$ Common carotid artery; $\mathbf{B}=$ Carotid bifurcation; $\mathbf{C}=$ Internal carotid artery; $\mathrm{P}=$ patients; $\mathbf{C}=$ controls.

Hypertension and dyslipidemia were more frequently present among patients. Prior stroke, CHD, family history of CVD, hypertension, dyslipidemia and smoking were less prevalent among young than among middle-aged patients, and smoking and high alcohol consumption were more common among male than among female patients.

\section{Carotid Intima-media thickness (cIMT)}

Values of mean IMT and RC are presented in Table 2 and significance of all tests applied is shown in Table 3. Mean IMT values were in all subgroups of patients and controls lowest in CCA and highest in BIF, and lower in young than in middle-aged participants. Sex-related differences were inconsistent. Mean values $<0.8 \mathrm{~mm}$ were mostly restricted to the young population and to controls. Mean values $\geq 1.0 \mathrm{~mm}$ were found in BIF in all patient and control subgroups but the young, and in ICA in middleaged patients and male patients and controls. Mean values $\geq 1.5 \mathrm{~mm}$ were solely found in middle-aged patients.

The RC between patients and controls was in all subgroups but males most distinct in ICA (20-35\%). Only middle-aged patients showed IMT increase compared to controls in CCA (19\%) and BIF (23\%). Statistical simulation suggested the need of $\mathrm{RC}>12 \%$ for CCA, $\mathrm{RC}>22 \%$ for BIF, and RC $>25 \%$ for ICA to detect cIMT-differences $\geq 80 \%$ between patients and controls, which matches our results fairly well.

Details on categorized segmental cIMT distribution are shown in Figure 2 and Table 3. IMT distribution was higher than that of controls in all patient subgroups but males in ICA. IMT distribution was further higher among middle-aged patients in CCA, and among middle-aged and male patients in BIF.

\section{Impact of risk factors on clMT}

Table 4 shows analysis of all participants $(n=234)$. Associations between RF and IMT increase varied in the different carotid segments, and across age and sex subgroups. With one exception (ICA in middle-aged participants), IMT increase was associated with age in all carotid segments among all subgroups. On the other hand, ICA in males was the only carotid segment in any subgroup, where patients' RF had a stronger impact on IMT increase than controls' $(\mathrm{p}=0.038)$.

\section{Discussion}

Our study presents cIMT data obtained from young and middle-aged patients after acute ischemic stroke. Previous studies on multisegmental RF-cIMT associations related to 
Table 4 Associations between vascular risk factors and segmental carotid IMT increase

\begin{tabular}{|c|c|c|}
\hline Participant group & Segment & Risk factor associations \\
\hline \multirow[t]{3}{*}{ Entire study population $(n=234)$} & CCA: & Age $(p<0.001)$; male sex $(p=0.023)$; hypertension $(p<0.001)$ \\
\hline & BIF: & Age $(p<0.001)$; dyslipidemia $(p=0.018) ; C H D(p=0.017)$; smoking $(p=0.012)$ \\
\hline & ICA: & Age $(p<0.001)$; dyslipidemia $(p=0.025)$; prior stroke $(p=0.009)$ \\
\hline \multirow[t]{3}{*}{ Age $15-44$ years $(n=66)$} & CCA: & Age $(p=0.001)$; hypertension $(p=0.008)$ \\
\hline & BIF: & Age $(p<0.001)$; hypertension $(p=0.009)$ \\
\hline & ICA: & Age $(p=0.002)$; family history of CVD $(p=0.039)$ \\
\hline \multirow[t]{3}{*}{ Age $45-60$ years $(n=168)$} & CCA: & Age $(p=0.05)$; male sex $(p=0.037)$; hypertension $(p=0.016)$ \\
\hline & BIF: & Age $(p=0.022) ;$ dyslipidemia $(p=0.033) ;$ smoking $(p=0.016)$ \\
\hline & ICA: & Dyslipidemia $(p=0.022)$; prior stroke $(p=0.037)$ \\
\hline \multirow[t]{3}{*}{ Females $(n=112)$} & CCA: & Age $(p<0.001)$; hypertension $(p=0.031)$ \\
\hline & BIF: & Age $(p<0.001)$; hypertension $(p=0.049)$ \\
\hline & ICA: & Age $(p<0.001)$ \\
\hline \multirow[t]{3}{*}{ Males $(n=122)$} & CCA: & Age $(p<0.001)$; hypertension $(p=0.012)$ \\
\hline & BIF: & Age $(p<0.001)$; dyslipidemia $(p=0.003)$; CHD $(p=0.031)$ \\
\hline & ICA: & Age $(p<0.001)$; dyslipidemia $(p=0.006)$, PAD $(p=0.028)$, prior stroke $(p=0.004)$ \\
\hline
\end{tabular}

$\mathrm{CCA}=$ Common carotid artery; $\mathrm{BIF}=$ Carotid bifurcation; $\mathrm{ICA}=$ Internal carotid artery.

incident stroke did either not include participants $<45$ years $[21,22]$, or did not provide acute phase cIMT data [23]. By combination of three statistical methods, we identified increased ICA-IMT as distinctly associated with incident stroke not only among middle-aged adults, as others described before [21], but also among young adults aged 15-44 years. Patients aged 15-44 showed a surprising $20 \%$ ICA-IMT increase compared to controls. Only a family history of CVD was found to be associated with increased ICA-IMT in the younger subgroup, which may reflect a genetic predisposition [24].

Female patients represent the best-controlled subgroup in this study. We found an unexpected ICA-IMT increase of $28 \%$ compared to female controls. The increase was surprisingly high compared to a $4 \%$ increase in CCA-IMT, and a $9 \%$ increase in BIF-IMT. In comparison, we found rather low and constant segmental differences (1-8\%) from controls in male patients, though their control group was less representative. The only factor related to ICA-IMT increase in females was age. Our results may reflect hormonal influences on the development of atherosclerosis [25-27]. ICA-IMT among male patients did not differ from controls'. However, male controls are insufficiently represented, what implies limitations for the interpretation of comparing results among males.

Our study shows a higher RF burden among patients, but also a high prevalence of RF among presumably healthy controls. Other studies have reported increasing risk of vascular events [28] and higher mortality proportional to RF burden [28-30], and recommended early preventive treatment. Our data strongly support broad preventive initiatives in families at risk.
We found an increasing RF burden with age, and the three most frequent RF were dyslipidemia (76\%), smoking (69\%) and hypertension (67\%). This is in accordance with other studies [19,31]. Our RF rates among patients are, however, higher than previously reported [31], as e.g. cholesterol levels among the Norwegian population remain high despite improvement during the last decades [32]. Our data further support that cIMT depends on age, sex and cardiovascular risk [15,33-36]. We found pronounced cIMT increase in middle-aged patients, which is in line with a recent young stroke study demonstrating substantial clinical and subclinical atherosclerosis [20].

The major strengths of NOR-SYS are the inclusion of CVD-free controls and the standardized ultrasound protocol. However, our study has limitations. The size of patient subgroups varies as a consequence of stringent stratification of our patient population. Accordingly, controls (the patients' partners) are unequally represented. Due to overall low case numbers, RF associations are in parts calculated with small sample sizes, which may have affected our results. Further, our data may be valid only for Caucasians, and may be influenced by the high risk profile of our population.

We did not account for multiple testing. However, as we performed approximately 100 tests, Bonferroni correction $(\mathrm{BC})$ would yield a corrected significance level of about $0.05 / 100=0.0005$, rounded to $\mathrm{p}<0.001$ in our study. Hence, associations with $\mathrm{p}<0.001$ would survive a BC. BC further reduces the number of type I errors at the cost of increasing the number of type II errors, and p-values above 0.0005 may still be indicative of an association. 


\section{Conclusions}

Stroke is associated with increased ICA-IMT already at a young age, related to a family history of CVD among the youngest patients and related to RF burden increasing with age. Also in CVD-free controls, RFs and subclinical atherosclerosis are prevalent. Our data suggest that vascular screening reveals established clinical and sub-clinical arterial disease requiring broad and aggressive treatment in order to prevent progressing CVD.

\section{Competing interests}

The authors declare that they have no competing interests.

\section{Authors' contributions}

AF designed the study, carried out the ultrasound examinations and data aquisition, participated in statistical analysis and data interpretation, and drafted the manuscript. ØAH participated in the design of the study, performed statistical analysis and data interpretation and drafted the manuscript. HN contributed with acquisition of data and critical revision of the manuscript for intellectual content. LT contributed with acquisition of data and critical revision of the manuscript for intellectual content and helped to draft the manuscript. UWA contributed to study design, data aquisition, statistical analysis and data interpretation, critical revision of the manuscript for intellectual content and drafted the manuscript. All authors read and approved the final manuscript.

\section{Acknowledgments}

The authors thank research nurse Linn Elin Rødal for her excellent work and assistance with data registration.

\section{Sources of funding}

University of Bergen, Norway, and The Western Norway Regional Health Authority.

\section{Author details \\ ${ }^{1}$ Centre for Neurovascular Diseases, Department of Neurology, Haukeland University Hospital, Bergen, Norway. ${ }^{2}$ Department of Clinical Medicine, University of Bergen, Bergen, Norway. ${ }^{3}$ Department of Global Public Health and Primary Health Care, University of Bergen, Bergen, Norway. ${ }^{4}$ Centre for age-related medicine, Stavanger University Hospital, Stavanger, Norway.}

Received: 7 March 2014 Accepted: 20 March 2014

Published: 26 March 2014

\section{References}

1. Kappelle LJ, Adams HP Jr, Heffner ML, Torner JC, Gomez F, Biller J: Prognosis of young adults with ischemic stroke. A long-term follow-up study assessing recurrent vascular events and functional outcome in the lowa Registry of Stroke in Young Adults. Stroke 1994, 25(7):1360-1365.

2. Putaala J, Haapaniemi E, Metso AJ, Metso TM, Artto V, Kaste M, Tatlisumak T: Recurrent ischemic events in young adults after first-ever ischemic stroke. Ann Neurol 2010, 68(5):661-671.

3. Waje-Andreassen U, Naess H, Thomassen L, Eide GE, Vedeler CA: Arterial events after ischemic stroke at a young age: a cross-sectional long-term follow-up of patients and controls in western Norway. Cerebrovasc Dis 2007, 24(2-3):277-282.

4. Bots ML, Grobbee DE: Intima media thickness as a surrogate marker for generalised atherosclerosis. Cardiovasc Drugs Ther 2002, 16(4):341-351.

5. Iwakiri T, Yano Y, Sato Y, Hatakeyama K, Marutsuka K, Fujimoto S, Kitamura K, Kario K, Asada Y: Usefulness of carotid intima-media thickness measurement as an indicator of generalized atherosclerosis: findings from autopsy analysis. Atherosclerosis 2012, 225(2):359-362.

6. Lorenz MW, Polak JF, Kavousi M, Mathiesen EB, Volzke H, Tuomainen TP, Sander D, Plichart M, Catapano AL, Robertson CM, Kiechl S, Rundek T, Desvarieux M, Lind L, Schmid C, DasMahapatra P, Gao L, Ziegelbauer K, Bots ML, Thompson SG, PROG-IMT Study Group: Carotid intima-media thickness progression to predict cardiovascular events in the general population (the PROG-IMT collaborative project): a meta-analysis of individual participant data. Lancet 2012, 379(9831):2053-2062.
7. Den Ruijter HM, Peters SA, Anderson TJ, Britton AR, Dekker JM, Eijkemans MJ, Engstrom G, Evans GW, De Graaf J, Grobbee DE, Hedblad B, Hofman A Holewijn S, Ikeda A, Kavousi M, Kitagawa K, Kitamura A, Koffijberg H, Lonn EM, Lorenz MW, Mathiesen EB, Nijpels G, Okazaki S, O'Leary DH, Polak JF, Price JF, Robertson C, Rembold CM, Rosvall M, Rundek T, et al: Common carotid intima-media thickness measurements in cardiovascular risk prediction: a meta-analysis. JAMA 2012, 308(8):796-803.

8. Fromm A, Thomassen L, Naess H, Meijer R, Eide GE, Krakenes J, Vedeler CA Gerdts E, Larsen TH, Kuiper KK, Laxdal E, Russell D, Tatlisumak T, WajeAndreassen U: The Norwegian Stroke in the Young Study (NOR-SYS): rationale and design. BMC Neurol 2013, 13(1):89.

9. Bots ML, Mulder PG, Hofman A, van Es GA, Grobbee DE: Reproducibility of carotid vessel wall thickness measurements. The Rotterdam Study. J Clin Epidemiol 1994, 47(8):921-930.

10. Chambless LE, Zhong MM, Arnett D, Folsom AR, Riley WA, Heiss G. Variability in B-mode ultrasound measurements in the atherosclerosis risk in communities (ARIC) study. Ultrasound Med Biol 1996, 22(5):545-554.

11. O'Leary DH, Polak JF, Kronmal RA, Manolio TA, Burke GL, Wolfson SK Jr: Carotid-artery intima and media thickness as a risk factor for myocardial infarction and stroke in older adults. Cardiovascular Health Study Collaborative Research Group. N Engl J Med 1999, 340(1):14-22.

12. Salonen $\mathrm{R}$, Haapanen A, Salonen JT: Measurement of intima-media thickness of common carotid arteries with high-resolution B-mode ultrasonography: inter- and intra-observer variability. Ultrasound Med Biol 1991, 17(3):225-230

13. Hollander M, Hak AE, Koudstaal PJ, Bots ML, Grobbee DE, Hofman A Witteman JC, Breteler MM: Comparison between measures of atherosclerosis and risk of stroke: the Rotterdam Study. Stroke 2003, 34(10):2367-2372.

14. Aminbakhsh A, Mancini GB: Carotid intima-media thickness measurements: what defines an abnormality? A systematic review. Clin Invest Med 1999, 22(4):149-157.

15. Chambless LE, Heiss G, Folsom AR, Rosamond W, Szklo M, Sharrett AR, Clegg $L X$ : Association of coronary heart disease incidence with carotid arterial wall thickness and major risk factors: the Atherosclerosis Risk in Communities (ARIC) Study, 1987-1993. Am J Epidemio/ 1997, 146(6):483-494.

16. Najjar SS, Scuteri A, Lakatta EG: Arterial aging: is it an immutable cardiovascular risk factor? Hypertension 2005, 46(3):454-462.

17. Touboul PJ, Hennerici MG, Meairs S, Adams H, Amarenco P, Bornstein N, Csiba L, Desvarieux M, Ebrahim S, Hernandez Hernandez R, Jaff M, Kownator S, Naqvi T, Prati P, Rundek T, Sitzer M, Schminke U, Tardif JC, Taylor A, Vicaut E, Woo KS: Mannheim carotid intima-media thickness and plaque consensus (2004-2006-2011). An update on behalf of the advisory board of the $3 \mathrm{rd}, 4$ th and 5 th watching the risk symposia, at the 13th, 15th and 20th European Stroke Conferences, Mannheim, Germany, 2004, Brussels, Belgium, 2006, and Hamburg, Germany, 2011. Cerebrovasc Dis 2012, 34 (4):290-296

18. Putaala J, Metso AJ, Metso TM, Konkola N, Kraemer Y, Haapaniemi E, Kaste $M$, Tatlisumak T: Analysis of 1008 consecutive patients aged 15 to 49 with first-ever ischemic stroke: the Helsinki young stroke registry. Stroke 2009, 40(4):1195-1203

19. Von Sarnowski B, Putaala J, Grittner U, Gaertner B, Schminke U, Curtze S, Huber R, Tanislav C, Lichy C, Demarin V, Basic-Kes V, Ringelstein EB, Neumann-Haefelin T, Enzinger C, Fazekas F, Rothwell PM, Dichgans M, Jungehulsing GJ, Heuschmann PU, Kaps M, Norrving B, Rolfs A, Kessler C, Tatlisumak T, sifap1 Investigators: Lifestyle risk factors for ischemic stroke and transient ischemic attack in young adults in the Stroke in Young Fabry Patients study. Stroke 2013, 44(1):119-125.

20. von Sarnowski B, Schminke U, Tatlisumak T, Putaala J, Grittner U, Kaps M, Tobin WO, Kinsella JA, McCabe DJ, Hennerici MG, Fazekas F, Norrving B, Kessler C, Rolfs A, sifap1 investigators: Prevalence of stenoses and occlusions of brain-supplying arteries in young stroke patients. Neurology 2013, 80(14):1287-1294.

21. Chambless LE, Folsom AR, Clegg LX, Sharrett AR, Shahar E, Nieto FJ, Rosamond WD, Evans G: Carotid wall thickness is predictive of incident clinical stroke: the Atherosclerosis Risk in Communities (ARIC) study. Am J Epidemiol 2000, 151(5):478-487.

22. Hofman A, Breteler MM, van Duijn CM, Janssen HL, Krestin GP, Kuipers EJ, Stricker BH, Tiemeier $H$, Uitterlinden AG, Vingerling JR, Witteman JC: The Rotterdam Study: 2010 objectives and design update. Eur J Epidemiol 2009, 24(9):553-572 
23. Waje-Andreassen U, Naess $H$, Thomassen L, Eide GE, Meijer R, Vedeler CA: Ultrasound, atherosclerosis and stroke at a young age: a cross-sectional long-term follow-up in western Norway. Eur J Neurol 2008, 15(5):512-519.

24. Traylor M, Farrall M, Holliday EG, Sudlow C, Hopewell JC, Cheng YC, Fornage M, Ikram MA, Malik R, Bevan S, Thorsteinsdottir U, Nalls MA, Longstreth W, Wiggins KL, Yadav S, Parati EA, Destefano AL, Worrall BB, Kittner SJ, Khan MS, Reiner AP, Helgadottir A, Achterberg S, Fernandez-Cadenas I, Abboud S, Schmidt R, Walters M, Chen WM, Ringelstein EB, O'Donnell M, et al: Genetic risk factors for ischaemic stroke and its subtypes (the METASTROKE collaboration): a meta-analysis of genome-wide association studies. Lancet Neurol 2012, 11(11):951-962.

25. Joakimsen O, Bonaa KH, Stensland-Bugge E, Jacobsen BK: Population-based study of age at menopause and ultrasound assessed carotid atherosclerosis: the Tromso Study. J Clin Epidemiol 2000, 53(5):525-530.

26. Witteman JC, Grobbee DE, Kok FJ, Hofman A, Valkenburg HA: Increased risk of atherosclerosis in women after the menopause. BMJ 1989, 298(6674):642-644.

27. Wellons M, Ouyang P, Schreiner PJ, Herrington DM, Vaidya D: Early menopause predicts future coronary heart disease and stroke: the Multi-Ethnic Study of Atherosclerosis. Menopause 2012, 19(10):1081-1087.

28. Putaala J, Haapaniemi E, Kaste M, Tatlisumak T: How does number of risk factors affect prognosis in young patients with ischemic stroke? Stroke 2012, 43(2):356-361.

29. Gjerde G, Naess H: Risk factor burden predicts long-term mortality after cerebral infarction. Acta Neurol Scand 2013. doi:10.1111/ane.12159. [Epub ahead of print].

30. Naess $\mathrm{H}$, Waje-Andreassen $\mathrm{U}$, Nyland $\mathrm{H}$ : Risk factor burden predicts long-term mortality in young patients with arterial cerebral infarction Acta Neurol Scand 2013, 127(2):92-96.

31. Putaala J, Yesilot N, Waje-Andreassen U, Pitkaniemi J, Vassilopoulou S, Nardi K, Odier C, Hofgart G, Engelter S, Burow A, Mihalka L, Kloss M, Ferrari J, Lemmen R, Coban O, Haapaniemi E, Maaijwee N, Rutten-Jacobs L, Bersano A, Cereda C, Baron P, Borellini L, Valcarenghi C, Thomassen L, Grau AJ, Palm F, Urbanek C, Tuncay R, Durukan-Tolvanen A, van Dijk EJ, de Leeuw FE, et al: Demographic and geographic vascular risk factor differences in European young adults with ischemic stroke: the 15 cities young stroke study. Stroke 2012, 43(10):2624-2630.

32. Jenum AK, Graff-Iversen S, Selmer R, Selmer R, Sogaard AJ: Risk factors for cardiovascular disease and diabetes through three decades. Tidsskr Nor Laegeforen 2007, 127(19):2532-2536.

33. De Groot E, Hovingh GK, Zwinderman AH, Wiegman A, Smit AJ, Kastelein JJ: Data density curves of B-mode ultrasound arterial wall thickness measurements in unaffected control and at-risk populations. Int Angiol 2005, 24(4):359-365.

34. Polak JF, Pencina MJ, Meisner A, Pencina KM, Brown LS, Wolf PA, D'Agostino RB Sr: Associations of carotid artery intima-media thickness (IMT) with risk factors and prevalent cardiovascular disease: comparison of mean common carotid artery IMT with maximum internal carotid artery IMT. J Ultrasound Med 2010, 29(12):1759-1768.

35. Bots ML, Hoes AW, Koudstaal PJ, Hofman A, Grobbee DE: Common carotid intima-media thickness and risk of stroke and myocardial infarction: the Rotterdam Study. Circulation 1997, 96(5):1432-1437.

36. Howard G, Manolio TA, Burke GL, Wolfson SK, O'Leary DH: Does the association of risk factors and atherosclerosis change with age? An analysis of the combined ARIC and CHS cohorts. The Atherosclerosis Risk in Communities (ARIC) and Cardiovascular Health Study (CHS) investigators. Stroke 1997, 28(9):1693-1701.

doi:10.1186/1756-0500-7-176

Cite this article as: Fromm et al: Risk factors and their impact on carotid intima-media thickness in young and middle-aged ischemic stroke patients and controls: The Norwegian Stroke in the Young Study. BMC Research Notes 2014 7:176.

\section{Submit your next manuscript to BioMed Central and take full advantage of:}

- Convenient online submission

- Thorough peer review

- No space constraints or color figure charges

- Immediate publication on acceptance

- Inclusion in PubMed, CAS, Scopus and Google Scholar

- Research which is freely available for redistribution

Submit your manuscript at www.biomedcentral.com/submit 